\title{
Cytotoxic and antiangiogenic activity of AW464 (NSC 706704), a novel thioredoxin inhibitor: an in vitro study
}

\author{
A Mukherjee', AD Westwell², TD Bradshaw², MFG Stevens², J Carmichael' and SG Martin*,I \\ 'Department of Clinical Oncology, City Hospital, University of Nottingham, Nottingham NG5 IPB, UK; ${ }^{2}$ School of Pharmacy, Centre for Biomolecular \\ Sciences, University of Nottingham, University Park, Nottingham NG7 2RD, UK
}

AW464 (NSC 706704) is a novel benzothiazole substituted quinol compound active against colon, renal and certain breast cancer cell lines. $\mathrm{NCl}$ COMPARE analysis indicates possible interaction with thioredoxin/thioredoxin reductase, which is upregulated under hypoxia. Through activity on HIFI $\alpha$, VEGF levels are regulated and angiogenesis controlled. A thioredoxin inhibitor could therefore exhibit enhanced hypoxic toxicity and indirect antiangiogenic effects. In vitro experiments were performed on colorectal and breast cancer cell lines under both normoxic and hypoxic conditions and results compared against those obtained with normal cell lines, fibroblasts and keratinocytes. Antiangiogenic effects were studied using both large and microvessel cells. Indirect antiangiogenic effects (production of angiogenic growth factors) were studied via ELISA. We show that AW464 exerts antiproliferative effects on tumour cell lines as well as endothelial cells with an $\mathrm{IC}_{50}$ of $\sim 0.5 \mu \mathrm{M}$. Fibroblasts are however resistant. Proliferating, rather than quiescent, endothelial cells are sensitive to the drug indicating potential antiangiogenic rather than antivascular action. Endothelial differentiation is also inhibited in vitro. Hypoxia $\left(1 \% \mathrm{O}_{2}\right.$ for $48 \mathrm{~h}$ ) sensitises colorectal cells to lower drug concentrations, and in HT29s greater inhibition of VEGF is observed under such conditions. In contrast, bFGF levels are unaffected, suggesting possible involvement of $\mathrm{HIFI}$. Thus, AW464 is a promising chemotherapeutic drug that may have enhanced potency under hypoxic conditions and also additional antiangiogenic activity.

British Journal of Cancer (2005) 92, 350-358. doi:I0.I038/sj.bjc.6602338 www.bjcancer.com

Published online 18 January 2005

(c) 2005 Cancer Research UK

Keywords: chemotherapy; hypoxia; thioredoxin; colorectal cancer and antiangiogenesis

Colorectal cancer is the fourth most common cancer in the world. Surgery is the mainstay of treatment of this tumour with chemotherapy being used in the adjuvant and palliative setting. 5-Fluorouracil remains the cornerstone of chemotherapy for colorectal cancer.

Angiogenesis, the growth of new blood vessels from pre-existing ones, is essential for the development of tumours (Folkman, 1990) as well as for invasion and metastasis. So an agent with both antitumour and antiangiogenic activity would be useful for colorectal cancer therapy.

AW464 (NSC 706704) is a novel benzothiazole substituted quinol compound with selective activity concentrated in certain colon (HCT116 and HT29), renal (CAKI-1 and ACHN) and breast cancer cell lines (MCF7, MDA-N and MDA-MB435) on the NCI panel (Wells et al, 2003). COMPARE analysis indicates possible interaction with thioredoxin/thioredoxin reductase signalling. The proposed molecular target of AW464, thioredoxin, belongs to a family of small $12 \mathrm{kDa}$ redox proteins that undergo NADPH dependent reduction by the enzyme thioredoxin reductase and in turn reduces oxidised cysteine group on proteins (reviewed by Powis and Montfort, 2001; Hirota et al, 2002). AW464 has been proposed to crosslink irreversibly to cysteine residues 32 and 35 of the thioredoxin active site via its two $\beta$-carbon atoms; the first link

*Correspondence: Dr SG Martin;

E-mail: stewart.martin@nottingham.ac.uk

Revised 10 November 2004; accepted 22 November 2004; published online 18 January 2005 is reversible, whereas the second crosslink is thought to be irreversible.

The effects of thioredoxin in the cell are pleiotropic, viz increasing cell proliferation through ribonucleotide reductase (Mau and Powis, 1992), prevention of apoptosis by inhibiting ASK-1 (Saitoh et al, 1998) and protection against oxidative stress through the activity of thioredoxin peroxidases (Powis and Montfort, 2001). Therefore, inhibition of thioredoxin can have antiproliferative and proapoptotic effects (Pallis et al, 2003). Thioredoxin is upregulated in a wide variety of tumours such as mesothelioma (Kahlos et al, 2001), leukaemia (Shao et al, 2001), lung (Kakolyris et al, 2001), hepatocellular (Miyazaki et al, 1998) and renal cancer (Lichtenfels et al, 2003). Colorectal cancer tissues have also been shown to overexpress thioredoxin and hence thioredoxin could be an important therapeutic target for colon cancer (Raffel et al, 2003). Preliminary immunohistochemical studies suggested that in normal human colon thioredoxin is found in the dividing crypt cells, while in colorectal cancer thioredoxin is overexpressed in cancer cells (Powis et al, 1998). Thioredoxin has also been reported to be upregulated during hypoxia (Berggren et al, 1996) and this, we hypothesise, may lead to increased AW464 efficacy under hypoxic conditions. Through its activity on HIF1 $\alpha$, thioredoxin can also regulate VEGF levels and hence angiogenesis (Welsh et al, 2002). A thioredoxin inhibitor such as AW464 may thus have both direct and indirect antiangiogenic effects and enhanced hypoxic toxicity.

This study aimed at studying the in vitro effects of AW464 on colorectal cancer and on angiogenesis. 


\section{MATERIALS AND METHODS}

\section{HUVEC isolation}

Human umbilical vein endothelial cells (HUVEC) were isolated from umbilical cords obtained from the Department of Obstetrics, City Hospital, Nottingham, by the collagenase perfusion technique (Jaffe et al, 1973). Briefly, the umbilical vein was cannulated and $5 \mathrm{ml}$ of prewarmed type 1 Collagenase (Lorne Laboratories, Twyford, UK) was infused through it. The free end of the cord was clamped and then incubated at $37^{\circ} \mathrm{C}$ in a $5 \% \quad \mathrm{CO}_{2}$ environment. The vein was flushed with $20 \mathrm{ml}$ of HUVEC medium and the isolated endothelial cells centrifuged at 1500 r.p.m. for $5 \mathrm{~min}$. The supernatant was aspirated and the pellet resuspended in $5 \mathrm{ml}$ of HUVEC medium and plated on a pregelatinised tissue culture flask (Sarstedt, UK). Cells isolated from at least two umbilical cords were pooled for further culture. Cells for experiments were used between passage 2 and 6 .

\section{Tumour and normal cells}

The colorectal cancer cell lines HT29, SW480, SW620 and the breast cancer cell line MCF7 (American Type Culture Collection) were chosen for this study. SW620 and SW480 form a matched pair of primary and metastatic population of cells from the same patient.

Several normal cell types, in addition to HUVEC, were used for comparison. These include MRCV lung fibroblasts (ECACC), NHDF (normal human dermal fibroblasts), NHEK (neonatal human epidermal keratinocytes) pooled (Cambrex, UK) and HUMMEC (human mammary microvessel endothelial cells) (a gift from Dr C Murray, University of Nottingham).

HT29 cells were used between passage 140 and 150, SW480 between 110 and 120, SW620 between 100 and 110, MCF7 between passage 20 and 30, MRCV between 22 and 26, NHDF between 3 and 8 and NHEK between 1 and 10. HT29 cells were grown in McCoy's 5a medium, SW620 and SW480 in L-15 medium and MCF7 in RPMI 1640 medium. All media were supplemented with $10 \% \mathrm{Fe}$ supplemented donor calf serum (PAA Laboratories, Somerset, UK), $1 \%$ penicillin - streptomycin (Sigma, Dorset, UK) and 1\% Lglutamine (Sigma). MEM medium for growth of MRCV fibroblasts was additionally supplemented with $1 \%$ HEPES buffer (Sigma), 1\% nonessential amino acids (Sigma) and $1 \%$ sodium bicarbonate (Sigma). NHDF fibroblasts and NHEK keratinocytes were grown in FGM-2 bullet-kit medium (Cambrex) and KGM bullet-kit medium (Cambrex), respectively. HUVEC and HUMMEC were grown in a 1:1 mix of Hams F12 medium (Sigma) and Medium 199 (Sigma), sterile water (Baxter, UK) supplemented with $20 \% \mathrm{Fe}$ supplemented donor calf serum (PAA laboratories, UK), $1 \%$ HEPES solution, $1 \%$ sodium bicarbonate, $1 \%$ penicillin-streptomycin, 1\% L-glutamine, $15000 \mathrm{U}$ of Heparin (CP Pharmaceuticals Limited, Wrexham, UK), $20 \mathrm{ng} \mathrm{ml}^{-1}$ bFGF and $5 \mathrm{ng} \mathrm{ml}^{-1}$ EGF (Peprotech, UK). All media were stored at $4{ }^{\circ} \mathrm{C}$ for no more than 1 month.

\section{Assays}

MTS assay Cells were plated on flat-bottomed 96-well plates (Nucleon, Riskily, Denmark) in a volume of $180 \mu \mathrm{l}$ of the respective culture medium at an appropriate seeding density for each cell line to ensure that cells were still in the exponential phase of growth at the end of the incubation period. These were 1000 cells per well for MCF7, HT29, HUVEC, HUMMEC, MRCV and NHDF and 5000 cells per well for SW620, SW480 and NHEK. For HUVEC, the 96-well plates were pregelatinised with $0.2 \%$ gelatin in PBS. After $24 \mathrm{~h}$ incubation, $20 \mu \mathrm{l}$ of $10 \times$ drug concentration were added to a triplicate of wells to achieve the drug concentration in a final volume of $200 \mu \mathrm{l}$. In total, $20 \mu \mathrm{l}$ of medium only or vehicle only (DMSO) were added to controls. After $72 \mathrm{~h}$ of incubation, $40 \mu \mathrm{l}$ of
MTS-PES reagent (Promega, Southampton, UK) were added to each well and incubated for a further $3 \mathrm{~h}$ for colour development. The incubation time was prolonged to $96 \mathrm{~h}$ for SW620 and $120 \mathrm{~h}$ for SW480 to ensure at least one doubling of absorbance. The time for development of formazan was also increased for these cell lines to $4 \mathrm{~h}$ instead of $3 \mathrm{~h}$. The absorbance was read from the plates at $492 \mathrm{~nm}$ on a plate reader. Absorbance levels from drug treated cells and untreated controls were corrected against medium only blank controls. The mean absorbance of drug treated wells was expressed as a percentage of nontreated controls to calculate the percentage proliferation status (Carmichael et al, 1987).

Growth assays Proliferation status of cells was also assessed by simple counting of cell number after treatment with drugs (Saunders et al, 1997). In total, $10^{5}$ cells of each cell line were plated out on six-well tissue culture plates (Corning, High Wycombe, UK) in a volume of $3 \mathrm{ml}$ of media. The cells were allowed to attach overnight, and then exposed to drugs for 24,48 and $72 \mathrm{~h}$. A pair of wells were washed with PBS, trypsinised and counted before drug treatment to give the number of cells before the addition of drug. This was taken as the $0 \mathrm{~h}$ time point. Further readings were conducted at 24,48 and $72 \mathrm{~h}$ after the addition of drug. Effects were also compared with drug treatment for $48 \mathrm{~h}$ of incubation under normoxic and hypoxic conditions. Hypoxia was achieved in a water-jacketed Thermoforma incubator gassed with nitrogen to achieve $1 \% \mathrm{O}_{2}$.

The effect of the drug on quiescent as opposed to proliferating endothelium were assessed by seeding HUVEC and HUMMEC in six-well plates at a density of $2 \times 10^{5}$ cells well $^{-1}$ and generating a growth curve. When cell numbers reached a plateau, media was aspirated off and replaced with either fresh media for controls or different drug dilutions of AW464 and treated for a further 24, 48 and $72 \mathrm{~h}$.

Cell survival assays While the MTS assay and the growth kinetic assays measure cell proliferation, cell survival assays measure reproductive integrity. These assays were performed according to the protocol of Liebmann et al (1993) with some modifications. Petri dishes $(100 \mathrm{~mm})$ (Corning, High Wycombe, UK) were plated with $5 \times 10^{5}$ cells in $10 \mathrm{ml}$ of media or $60-\mathrm{mm}$ Petri dishes were plated with $1.8 \times 10^{5}$ cells in $3.5 \mathrm{ml}$ of media. The cells were allowed to attach for $24 \mathrm{~h}$. Media was aspirated off and the exponentially growing cells were then exposed to drug for $72 \mathrm{~h}$, following which they were trypsinised and plated out for colony formation. Incubation time was 4 weeks for all tumour cell lines except SW620 (3 weeks), 2 weeks for fibroblasts and 10 days for HUVEC. Finally, colonies were fixed with methanol (Fisher Scientific, Loughborough, UK) and stained with $1 \%$ crystal violet (Sigma) vide a protocol modified from Freshney (1994). Colonies were counted by eye and confirmation by microscopy carried out as necessary. Any cluster of cells greater than 50 in number was counted as a colony. All survival points were in triplicate and experiments repeated at least twice.

Tube formation studies on Matrigel The method was adapted from Dicker et al (2001). Petri dishes $(100 \mathrm{~mm})$ were plated with $5 \times 10^{5}$ HUVEC cells in $6 \mathrm{ml}$ of media. The cells were allowed to attach for $24 \mathrm{~h}$. The media was aspirated off and exponentially growing cells were then exposed to $6 \mathrm{ml}$ of the $\mathrm{IC}_{50}$ dose of control drugs paclitaxel, fumagillin and AW464 for $72 \mathrm{~h}$. For each drug treated condition or control, 50000 cells in $200 \mu$ l of media were then added to wells of a 24 -well plate precoated with Matrigel at room temperature, for $1 \mathrm{~h}$. Cells were then incubated at $37^{\circ} \mathrm{C}$ and $5 \% \mathrm{CO}_{2}$ for $48 \mathrm{~h}$. Photographs were taken for assessment of tube formation on Matrigel at $24 \mathrm{~h}$ postplating.

Indirect antiangiogenic effects Indirect antiangiogenic effects of AW464 were estimated by effects on the production of angiogenic 
growth factors by tumour cell lines. Cells were plated onto six-well plates at a density of $1 \times 10^{5}$ cells for untreated controls and $2 \times 10^{5}$ cells for drug treated conditions. After attachment overnight, media was aspirated off and $3 \mathrm{ml}$ of different AW464 dilutions or media only were added to the wells. The cells were incubated for a total of $72 \mathrm{~h}$. For the last 24 or $48 \mathrm{~h}$ of the incubation period, cells were exposed either to normoxic or hypoxic $\left(1 \% \mathrm{O}_{2}\right)$ conditions. The supernatant was centrifuged at 2000 r.p.m. for $5 \mathrm{~min}$ to remove debris, aliquoted out and stored at $-80^{\circ} \mathrm{C}$ until further use. ELISAs for VEGF and bFGF were conducted according to R\&D systems duo-set protocols (Ishibashi et al, 2001). Plates were read on a plate reader at $405 \mathrm{~nm}$. VEGF and bFGF production per cell was calculated from the standard curves obtained.

\section{Statistical analysis}

A Student's $t$-test was used to calculate probability values and $P<0.05$ was considered to be statistically significant (indicated by * on graphs).

\section{RESULTS}

\section{Cytotoxic effect of AW464 on tumour and endothelial cells}

Both MTS assays (Figure 1) and growth curve experiments (Figure 2) with AW464 demonstrate that the drug inhibits cell proliferation for all tumour cell lines (HT29, SW480, SW620 and MCF7) as well as endothelial cells (HUVEC). The maximum antiproliferative effect is evident after $72 \mathrm{~h}$ drug incubation. The $\mathrm{IC}_{50}$ (50\% growth inhibitory concentration) lies between 0.1 and $1 \mu \mathrm{m}$. Cell survival assays, conducted subsequently at the $\mathrm{IC}_{50}$ dose $(0.5 \mu \mathrm{M})$, showed a decrease in clonogenic survival indicating a cytotoxic rather than cytostatic mechanism of action. This profile of action of AW464 was quite similar to the control drug paclitaxel, which also showed a cytotoxic effect on all tumour cell lines as well as endothelial cells (data not shown). MRCV fibroblasts, however, exhibited a relative resistance to the drug (Figure 3). This differential sensitivity was further explored in later experiments (see later).

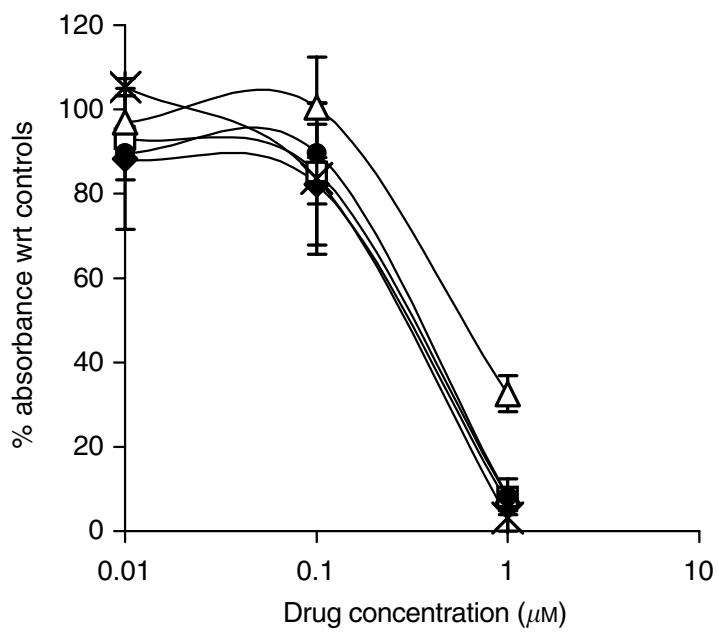

Figure I MTS assay results: percentage absorbance as compared to

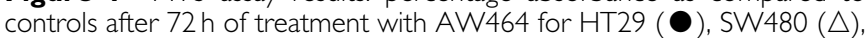
SW620 $(\triangle)$, MCF7 $(\bullet)$ and HUVEC $(*)$ cell lines. Data points were in triplicate in individual experiments and error bars represent standard error of means.

\section{AW464 inhibits endothelial tube differentiation}

Angiogenesis is a stepwise process where endothelial cells must differentiate into tubes to form new vessels. The effects of the drugs were therefore assessed not only on the proliferation of endothelial cells but also on the ability to differentiate into tubes on a basement membrane matrix, Matrigel. Matrigel is a solubilised basement membrane preparation extracted from the Engelbreth-Holm-Swarm mouse sarcoma. Its major components are laminin, collagen IV and heparan sulphate proteoglycans. HUVEC differentiate into capillary like structures on Matrigel in the presence of serum and growth factors. The formation of tube like vessels on Matrigel can therefore be used to assess compounds that either stimulate or inhibit angiogenesis (Ponce, 2001). AW464 inhibited endothelial differentiation at the $\mathrm{IC}_{50}$ dose as evident from tubal abortion at both 24 and $48 \mathrm{~h}$ postplating (data not shown). The effects were comparable to the control drugs, paclitaxel and fumagillin.

\section{Fibroblasts are relatively resistant to AW464}

The effect of AW464 on the proliferation of different normal cell lines was investigated using the MTS assay (Figure 4). Both large (HUVEC) and microvessel (HUMMEC) endothelial cells and keratinocytes (NHEK) were as sensitive as the tumour lines to the drug with an $\mathrm{IC}_{50}$ of $\sim 0.5 \mu \mathrm{M}$. Fibroblasts (NHDF and MRCV) were relatively resistant to the $\mathrm{IC}_{50}$ dose (Figure $4 \mathrm{~A}$ ). As the drug dose increases to $1 \mu \mathrm{M}$, the MRCV cells become sensitive to the drug but the differential with NHDFs still applies as they are resistant in comparison to the other cell lines $(P<0.05)$ (Figure 4B).

\section{AW464 may be more effective under hypoxic conditions}

As thioredoxin and thioredoxin reductase have been shown to be upregulated under hypoxic conditions (Berggren et al, 1996), we investigated whether a potential thioredoxin inhibitor such as AW464 could be more effective under hypoxic conditions. On $48 \mathrm{~h}$ of exposure to hypoxia, lower doses of AW464 (0.1-0.001 $\mu \mathrm{M})$ that had very little effect under normoxic conditions, were effective in decreasing proliferation (Figure $5 \mathrm{~A}-\mathrm{C}$ ). There was approximately a five-fold reduction in the $\mathrm{IC}_{50}$ (to $\sim 0.1 \mu \mathrm{M}$ ) for all the colorectal cancer cell lines under hypoxic conditions. These results indicate that AW464 may be more effective under hypoxic conditions.

\section{Quiescent endothelial cells are resistant to AW464}

Antiangiogenic agents should be effective only against proliferating endothelial cells in contrast to antivascular agents that cause vascular shutdown. In order to investigate whether the effect of AW464 on endothelial cells was antiangiogenic, we considered the effects of AW464 on quiescent as opposed to proliferating endothelial cells (Figure 6A(a,b)). AW464 was effective against proliferating large (HUVEC) and microvessel (HUMMEC) endothelial cells but quiescent cells were resistant to the drug over the whole dose range $(0.1-1 \mu \mathrm{M})$ after 24,48 and $72 \mathrm{~h}$ of exposure (Figure $6 \mathrm{~B}(\mathrm{a}, \mathrm{b})$ ). Thus, the mechanism of action of the drug on endothelial cells is potentially antiangiogenic rather than antivascular, although confirmation by in vivo experimentation is required.

\section{Indirect antiangiogenic effects of AW464}

Angiogenesis may depend on growth factor production from tumour cells to stimulate the endothelial cells via a paracrine loop. The effect of AW464 on growth factor production was investigated under both normoxic and hypoxic conditions. Low doses of the 

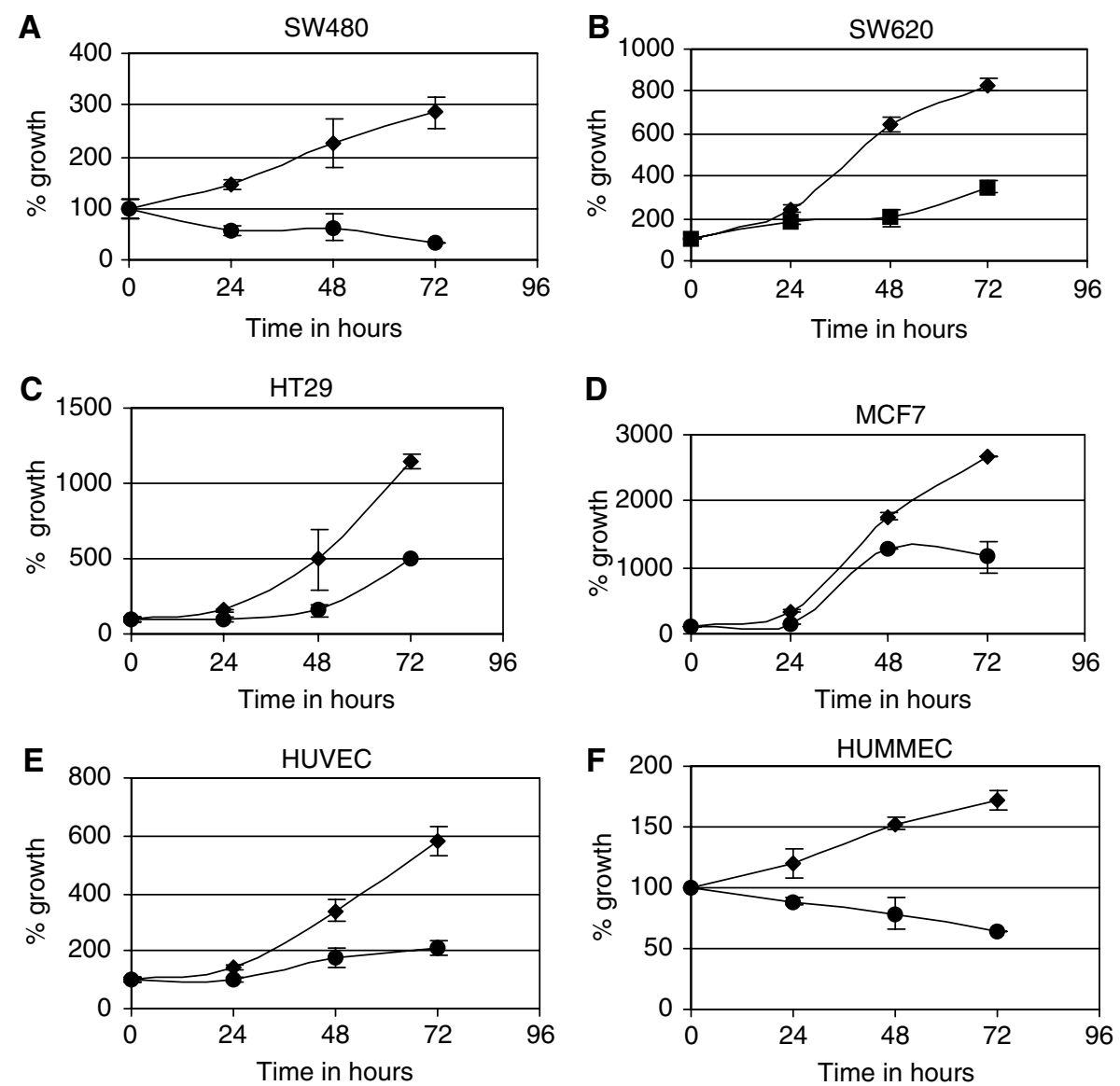

Figure 2 Temporal plots showing action of IC 50 AW464 ( $)$ and untreated controls ( $\bullet$ ) on SW480 (A), SW620 (B), HT29 (C), MCF7 (D), HUVEC (E) and HUMMEC (F) at 24, 48 and $72 \mathrm{~h}$ time points. \% growth compared to $0 \mathrm{~h}$ time point (time of drug addition) was plotted in duplicate and error bars represent standard deviation.

Clonogenic survival: $\mathrm{IC}_{50}$ AW464 (72 h)

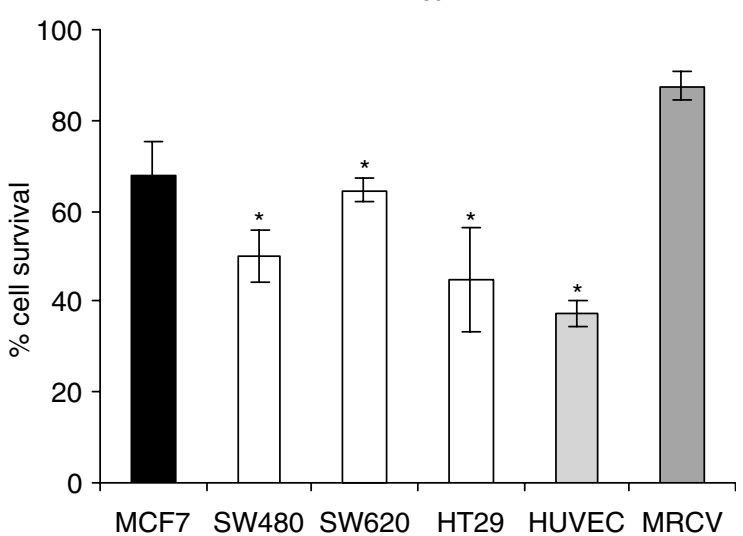

Figure 3 Mean clonogenic cell survival of cells treated with $I C_{50}$ AW464. Data pooled from two experiments with error bars representing standard error of means. Plating efficiencies of individual cell lines with standard error were as follows: MCF7 - $55 \pm 5 \%$; SW $480-20 \pm 5 \%$; SW $620-40 \pm 13 \%$; HT29 - II $\pm 0.3 \%$; HUVEC - 22 $\pm 2 \% ;$ MRCV $-31 \pm 1 \%$.

drug $\left(<\mathrm{IC}_{50}\right)$ cause a decrease in VEGF production (Figure 7A, B). VEGF was upregulated under hypoxic conditions in colorectal cell lines but not by a significant amount. The relative decrease in
VEGF levels following AW464 treatment was greater under hypoxic than under normoxic conditions in the HT29 cell line (Figure 7A, B). In contrast, none of the tumour cell lines produced bFGF under normoxic or hypoxic conditions and AW464 had no effects on basal levels (not shown). Since VEGF, unlike bFGF, is under the regulation of HIF $1 \alpha$, such results suggest that HIF $1 \alpha$ may be potentially affected by the drug.

\section{DISCUSSION}

Chemotherapy for colorectal cancer is predominantly used in the adjuvant setting for advanced and metastatic disease. 5-Flourouracil and in recent years, irinotecan, have been the two commonly used drugs for treating this cancer. Unfortunately, median survival for advanced disease is still poor (14.8-17.4 months) (Berlin, 2002). Dukes' staging remains the most important prognostic factor for colorectal cancer. In the search for new targets for prognosis and survival, several studies have focused on angiogenesis. Some have indicated a positive correlation between angiogenesis and prognosis of colorectal cancer (Frank et al, 1995; Pantalone et al, 1999), while others have failed to be conclusive (Bossi et al, 1995; Lee et al, 2000). Among other molecules, thioredoxin has also been shown to be an important prognostic factor for colorectal cancer (Raffel et al, 2003) and involved with colorectal carcinogenesis (Berggren et al, 1996, Lechner et al, 2002). Thioredoxin/thioredoxin reductase signalling therefore may be a novel pathway to target in this malignancy. Thioredoxin and 

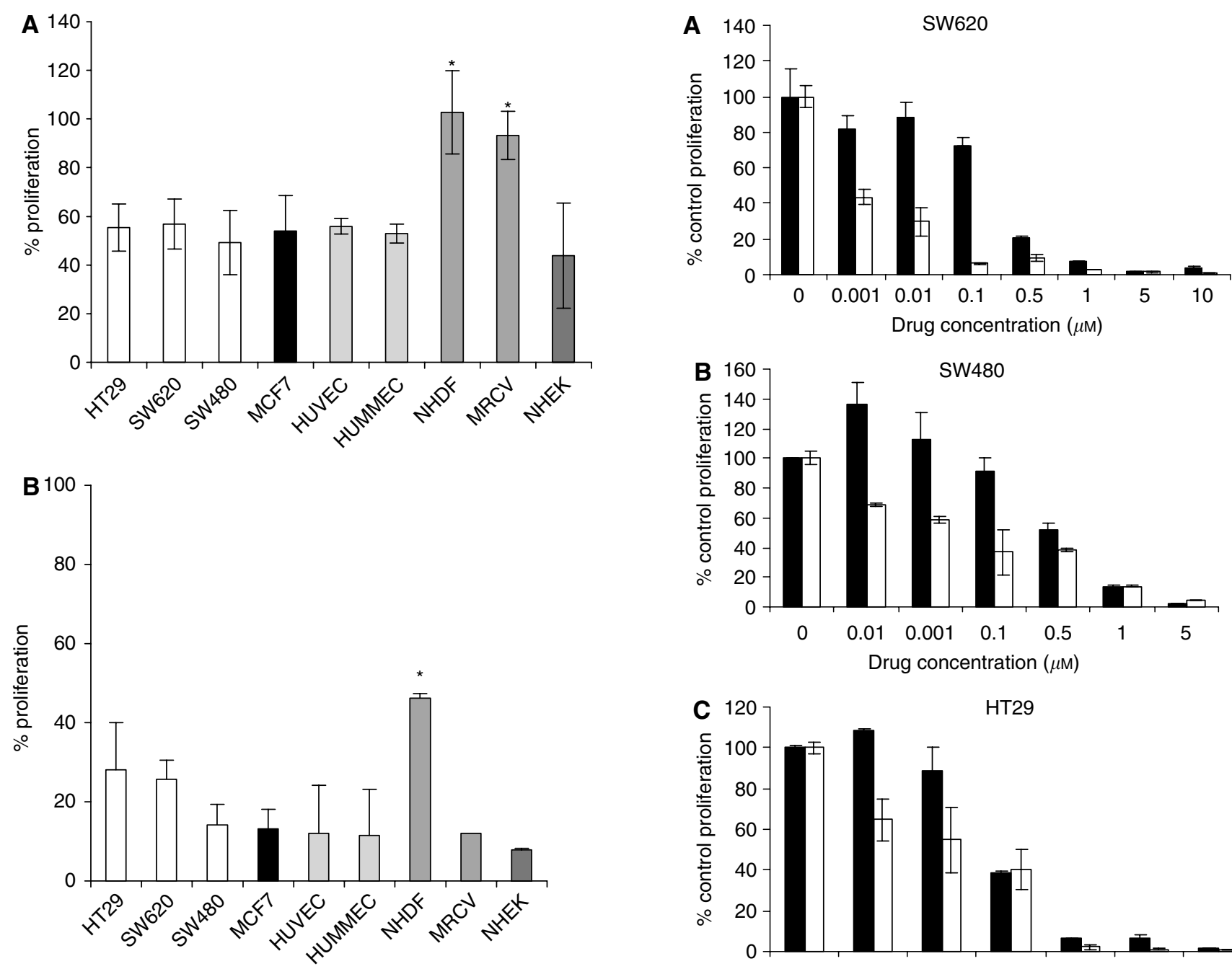

Figure 4 MTS assay results: percentage proliferation as compared to controls after $72 \mathrm{~h}$ of treatment with $0.5 \mu \mathrm{M}\left(\mathrm{IC}_{50}\right)(\mathbf{A})$ and I $\mu \mathrm{M}(\mathbf{B})$ AW464. Data points were in triplicate in individual experiments and error bars represent standard error of means.

thioredoxin reductase are also important proteins present in endothelial cells to tackle oxidative stress (Fernando et al, 1992; Anema et al, 1999). So a putative thioredoxin inhibitor may have potential antiangiogenic activity.

The novel drug, AW464, on COMPARE analysis and database mining, was thought to be involved in thioredoxin/thioredoxin reductase signalling. On microarray analysis at the NCI, after treatment of HCT116 cells with $1 \mu \mathrm{M}$ AW464 for $24 \mathrm{~h}$, the only gene found to be upregulated was thioredoxin reductase (Westwell et al, 2003).

In our study, the drug was found to inhibit cell proliferation in colorectal and breast tumour cell lines as well as HUVEC with an $\mathrm{IC}_{50}$ of $\sim 0.5 \mu \mathrm{m}$. The antiproliferative effect of a thioredoxin inhibitor may be attributed to the decrease in transfer of reducing equivalents to ribonucleotide reductase from active thioredoxin, leading to decreased DNA synthesis. The effect of the drug at the $\mathrm{IC}_{50}$ dose was cytotoxic rather than cytostatic as evident by a decrease in clonogenic survival. In contrast, the proliferation and clonogenic survival of fibroblasts MRCV was unaffected. This led to investigations for relative sensitivities of different cell lines. Both large, HUVEC and microvessel endothelial cells, HUMMEC were found to be as sensitive to the drug as tumour cells.
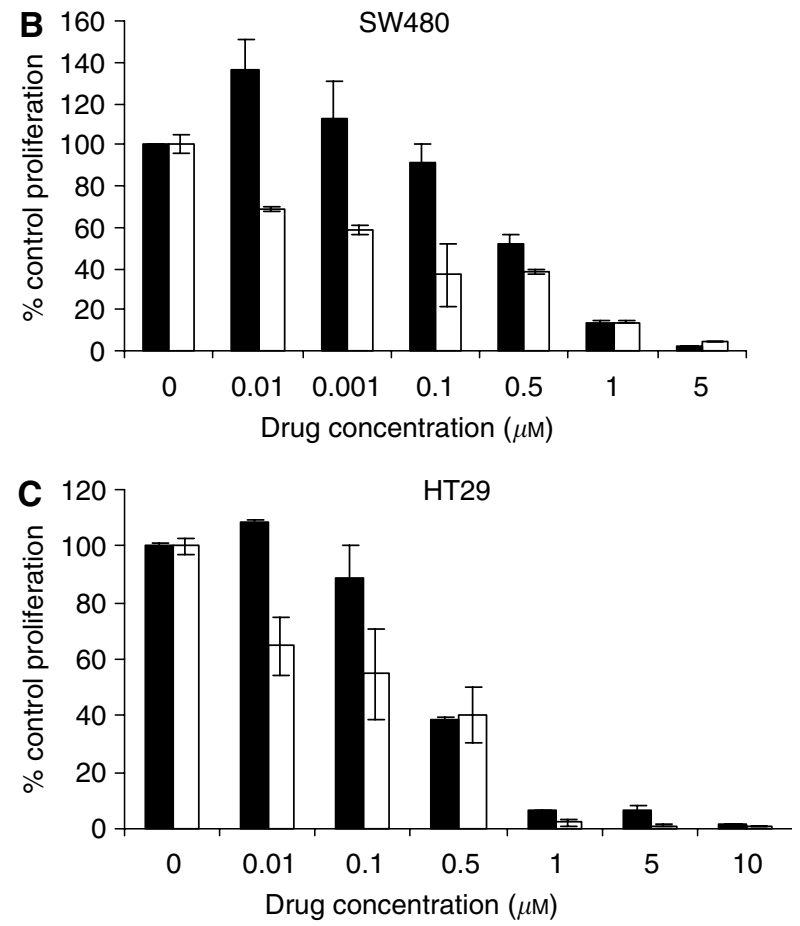

Figure 5 Effects of AW464 on SW620 (A), SW480 (B) and HT29 (C) under normoxia $(\mathbf{O})$ and hypoxia $\left(1 \% \mathrm{O}_{2}\right)(\square)$ for $48 \mathrm{~h}$ compared by growth assays. Results were normalised to respective controls with standard deviation depicted as error bars. Mean control cell numbers ( $\times 10^{4}$ cells) were as follows: SW 620: 31.25 (normoxia); 19.75 (hypoxia) SW480: 37.25 (normoxia); 23 (hypoxia); HT29: 19.87 (normoxia); 17.37 (hypoxia).

Thioredoxin and thioredoxin reductase have been identified as major redox proteins in HUVEC (Fernando et al, 1992; Anema et $a l, 1999)$ and therefore inhibition of thioredoxin should have direct antiproliferative effects. This was corroborated by this study. The sensitivity of microvessel endothelial cells, HUMMEC, was important as angiogenesis involves the proliferation of microvessel endothelial cells. Inorganic arsenic, another compound that can target the thioredoxin system, has also been shown to be toxic to rat heart microvessel endothelial cells in its trivalent form (Hirano et al, 2003) and inhibits endothelial cell proliferation in vitro and angiogenesis in vivo (Don et al, 2003). Both fibroblast cell lines, NHDF and MRCV, are resistant to the $\mathrm{IC}_{50}$ dose of AW464. With an increase in dose to $1 \mu \mathrm{M}$, fibroblasts also become sensitive to AW464; but in comparison to other cell lines dermal fibroblasts are still relatively resistant. Epidermal keratinocytes, on the other hand, are sensitive. The relative resistance of the fibroblasts cannot be explained by proliferation differences alone and some under- 
A
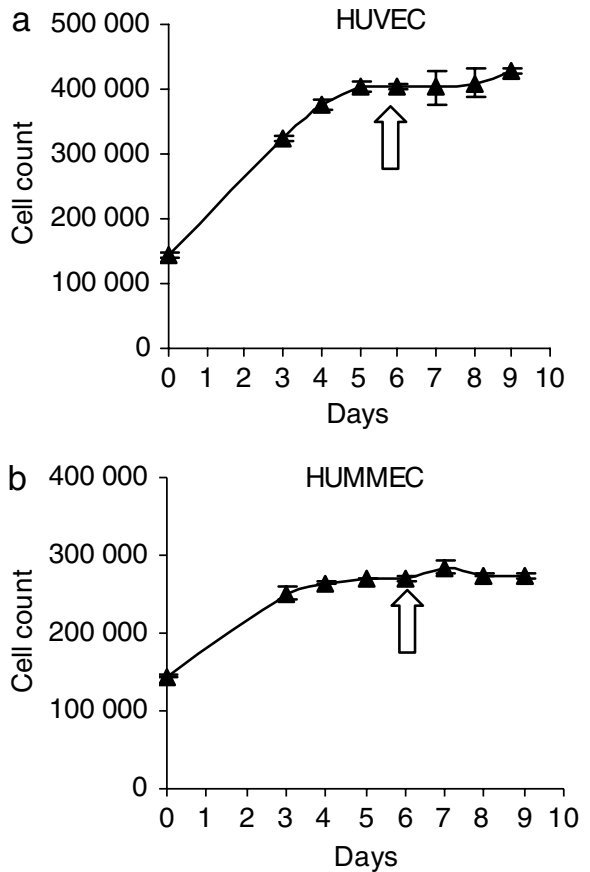

B
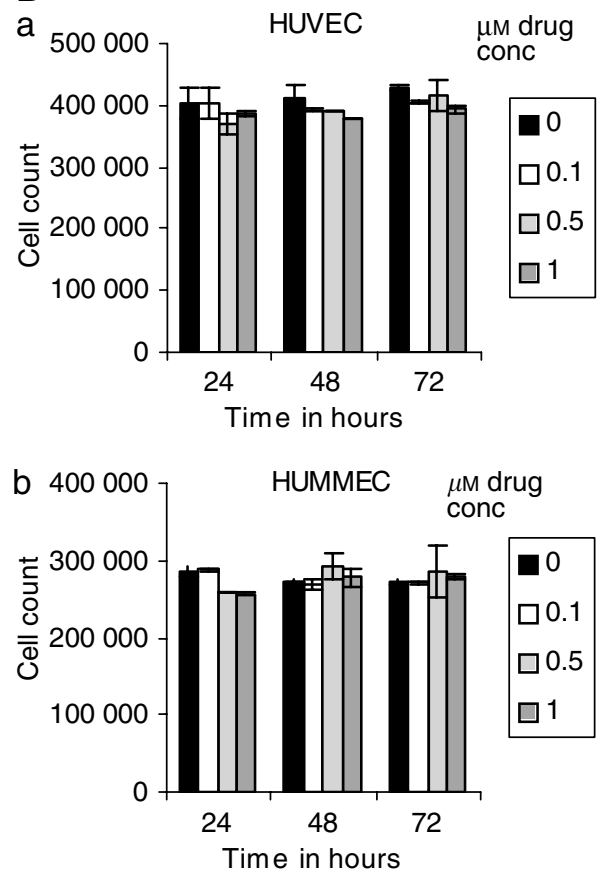

Figure 6 (A) (a) HUVEC and HUMMEC (b) were grown to quiescence as indicated by cell numbers on the growth curves. (B) At this time-point (arrow), HUVEC (a) and HUMMEC (b) were exposed to different doses of AW464 (no drug control; 0. I; 0.5; I $\mu \mathrm{M}$ ) and cell numbers were assessed 24, 48 and $72 \mathrm{~h}$ later. Readings are from one representative experiment and error bars represent standard deviation.

lying factor such as differential thioredoxin levels may explain this phenomenon and warrants further investigation. For example, it is known that high levels of thioredoxin are present in epidermal keratinocytes to protect against UV-B-induced skin injury (Schallreuter and Wood, 2001), and this may explain the sensitivity of keratinocytes to AW464. Differential sensitivity assays in vitro may be a pointer of drug toxicities in vivo. Dermal reactions may therefore be predicted as a toxicity of the drug. Since pulmonary fibroblasts MRCV are relatively resistant, lung toxicities may potentially be minimised.

An antiangiogenic agent should be active only against proliferating and not quiescent endothelial cells, in contrast to antivascular agents. AW464 was found to affect only proliferating endothelial cells, whereas quiescent cells were resistant. The mechanism of action on endothelial cells is thus potentially antiangiogenic rather than antivascular. In addition to there being little effect on normal vasculature there may be significant therapeutic implications in that AW464 may have to be administered chronically or in combination with other agents rather than it being used acutely if it were a tumour vascular targeting agent. Further in vivo characterisation is required to confirm whether the drug is a pure antiangiogenic agent or whether it exhibits any antivascular action.

Another therapeutic problem common in tumours is the hypoxic cells at the core that are often resistant to traditional modes of therapy. Thioredoxin expression however is increased under hypoxic conditions (Berggren et al, 1996) and hence a thioredoxin inhibitor, we hypothesised, could be more effective under hypoxic conditions. The increased antiproliferative effect of lower doses of AW464 observed under hypoxia may ensure better eradication of the hypoxic population of cells. A low-dose AW464 strategy may thus be combined with radiation or other chemotherapeutic agents that target the oxic cells for greater therapeutic efficacy.
The hypoxic upregulation of thioredoxin also has indirect effects on angiogenesis. Thioredoxin transfection has been shown to increase HIF $1 \alpha$ transactivation activity and the protein products of hypoxia-responsive genes such as VEGF and nitric-oxide synthase in MCF7 breast and HT29 colon cancer cell lines under both aerobic and hypoxic conditions (Welsh et al, 2002). In the current study, low doses of AW464 $\left(<\mathrm{IC}_{50}\right)$ were found to inhibit the production of VEGF and such inhibition was greater under hypoxic conditions. Thioredoxin is known to be upregulated under hypoxia and transfers reducing equivalents to the dual function DNA repair endonuclease Refl and thence to HIF1 $\alpha$ (Ema et al, 1999). It then dimerises with HIF $1 \beta$ to activate downstream factors such as VEGF. Thus, a thioredoxin inhibitor such as AW464 may stop the transfer of sulphhydryl moieties to HIF1 $\alpha$ and thereby downregulate VEGF more effectively, as seen in this study, under hypoxic conditions. The colorectal cancer cell lines in this study produced low levels of angiogenic growth factors. AW464 was efficacious in lowering these levels even further, and this indicates that the effect of the drug may be more marked for cell lines that produce high levels of endogenous growth factors. In contrast, bFGF levels were unaffected by the drug or hypoxia. Unlike the HIF1 $\alpha$-VEGF signalling pathway, hypoxia induced bFGF expression is mediated through the JNK signal transduction pathway (Le and Corry, 1999). This differential regulation is an indicator that HIF $1 \alpha$ may be affected by AW464 and experiments are currently underway to examine this. PX-12 (a thioredoxin inhibitor) (Welsh et al, 2003a), and pleurotin and PX478 (thioredoxin reductase inhibitors) (Powis et al, 2003; Welsh et al, 2003b, 2004) have already been characterised as inhibitors of HIF1 $\alpha$. However, these thioredoxin inhibitors target the Cys73 of thioredoxin unlike AW464 that is postulated to target Cys 32 and 35 .

The decrease in VEGF production at low doses of AW464 $\left(<\mathrm{IC}_{50}\right)$ under normoxic conditions could probably be explained due to the fact that there are also normoxic pathways regulating 

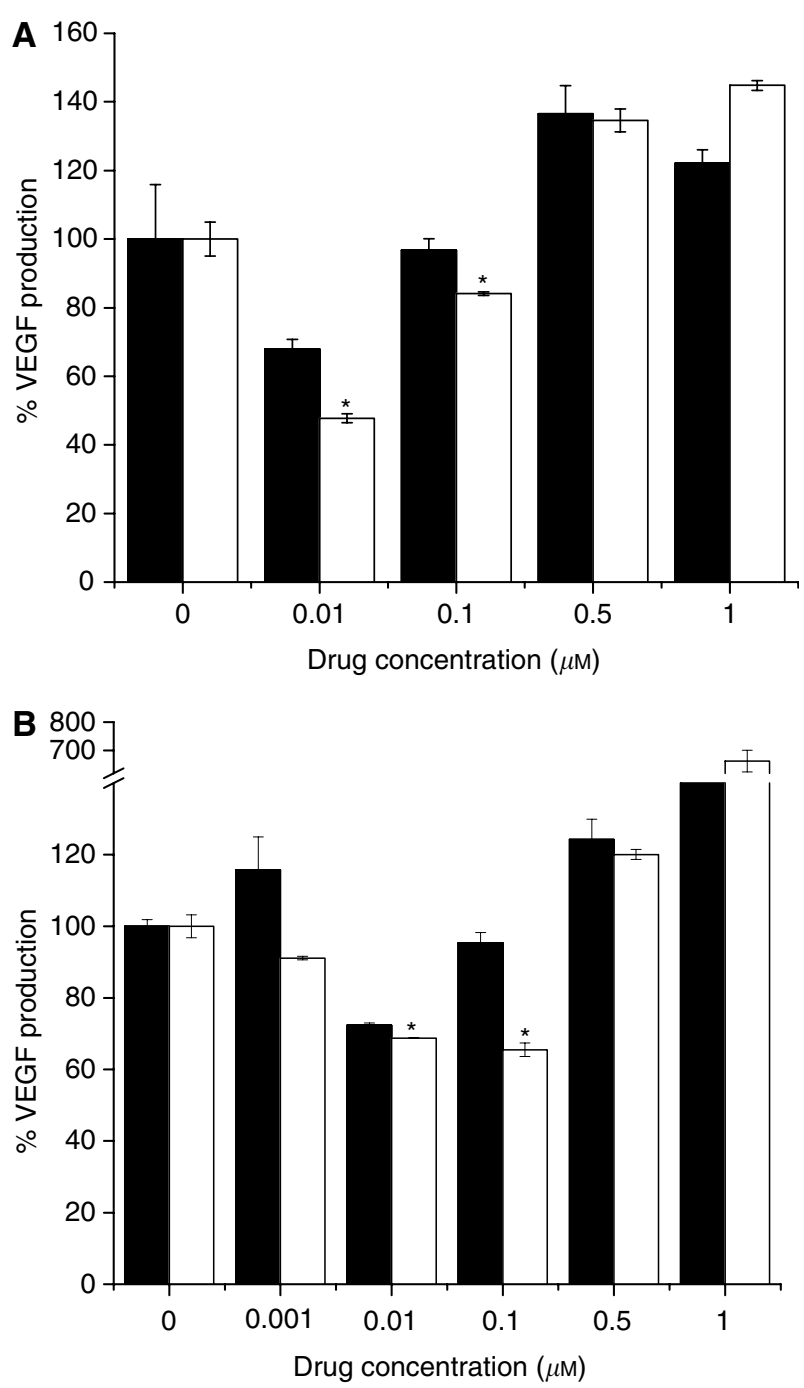

Figure 7 \% VEGF production wrt controls at different doses of AW464 under normoxic ( $\mathbf{\square})$ and hypoxic $(\square)$ conditions in HT29: 24 (A) and 48 (B) hours of hypoxia. Data from one representative experiment with standard deviation.

HIF1 $\alpha$. One of these is the PI3 kinase pathway (Zhong et al, 2000; Chun et al, 2002). Thioredoxin has been shown to regulate this pathway by inhibiting PTEN, which in turn is a negative regulator of the PI3K pathway (Meuillet et al, 2004). Hence, thioredoxin inhibitors such as AW464 might indirectly impact on angiogenesis through pathways affecting HIF1 $\alpha$ under normoxic and hypoxic conditions. The increase in VEGF production at higher doses of AW464 probably represents a stress response, as high doses of chemotherapy have been known to induce VEGF production. In clinical trials with VEGF receptor tyrosine kinase inhibitors, VEGF serum levels increased in patients treated by high doses (Drevs, 2003). Also, heat shock proteins, hsp70 and hsp105, have been shown to be induced at high doses of AW464 in NCI microarrays. Heat shock proteins stabilise HIF1 by preventing its degradation (Zhou et al, 2004) and may be involved in this stress response. It should however be borne in mind that the regulation of VEGF expression is quite complex, occurring at transcriptional, posttranscriptional and translational levels and is not exclusively dependent on HIF1 (reviewed by Xie et al, 2004). A thioredoxin inhibitor such as AW464 is most likely to inhibit the HIF1 and its associated signalling pathways (e.g. PI3K and Ras pathways) and future assays (macro/microarrays, transactivation assays and Westerns) have been contemplated to further characterise the inhibition at the molecular level.

The efficacy of low doses of AW464 in decreasing proliferation under hypoxic conditions and also decreasing VEGF levels may be utilised by low-dose scheduling of the drug. Recent studies have shown that frequent administration in vivo of low doses of chemotherapeutic drugs ('metronomic' dosing) can affect tumour endothelium and inhibit tumour angiogenesis, reducing significant side effects (e.g., myelosuppression) (Browder et al, 2000; Gately and Kerbel, 2001; Bocci et al, 2002). VEGF is not only a proangiogenic factor but can also cause drug/radiation resistance, inhibit apoptosis, impair drug delivery and act as a tumour cell survival factor (reviewed by Harmey and Bouchier-Hayes, 2002). Therefore, lower doses of AW464 that inhibit VEGF, may abrogate all these harmful effects in addition to indirectly preventing angiogenesis. Targeting VEGF may be an important therapeutic tool in colorectal cancer as shown by recent phase II clinical trial results with bevacizumab, a recombinant monoclonal antibody to VEGF (Kabbinavar et al, 2003). Time to progression was longer in patients receiving bevacizumab and 5FU-leucovorin than those receiving 5-FU leucovorin alone (9.2 vs 5.2 months) (Berlin, 2002). Thus AW464, with its chemotherapeutic and antiangiogenic potential, may be a worthwhile drug for colorectal cancer therapy. Since the subtoxic doses of the drug are most effective in decreasing proliferation under hypoxic conditions and in reducing VEGF levels, it will probably be used as combination therapy without itself causing serious side effects.

From current results, we conclude that AW464, a novel thioredoxin inhibitor, is an effective drug in vitro against tumour cells. The added advantage is that its effects may be potentiated under hypoxic conditions at low doses. Fibroblasts are relatively resistant to AW464 and hence some normal tissues may be differentially spared. Potential antiangiogenic effects of the drug are evident in its specificity for proliferating endothelial cells, inhibition of endothelial tube differentiation and reduction in VEGF levels at low doses. bFGF is however unaffected and hence HIF $1 \alpha$ inhibition is now being investigated. The drug warrants further experimentation, especially in vivo, to prove its antitumour and antiangiogenic effects. While in vitro results may not always correlate with in vivo effects, initial characterisation of novel agents is often conducted in appropriate in vitro models. For example, the NCI screen for antiangiogenic agents uses in vitro proliferation, tube differentiation on Matrigel and chemotaxis assays in Boyden chambers; a compound positive for effects on any one of these assays is carried forward for in vivo analysis. Some preliminary studies for antitumour effects have been conducted with human renal cell carcinoma RXF 944XL hypernephroma xenografts in nude mice (Wells et al, 2003). Treatment with AW464 $15 \mathrm{mg} \mathrm{kg}^{-1}$ on day 1 and day 8 produced $57 \%$ growth retardation; treatments on day 1 and 2 produced a growth inhibition of $73 \%$. In HT29 colon xenograft studies, 14 days posttreatment with AW464, there was a tumour growth delay of 7 days accompanied by $42.5 \%$ growth inhibition. Further assays are currently being conducted to validate thioredoxin as the potential drug target and elucidate whether HIF1 $\alpha$ may be inhibited as a consequence. Thioredoxin motifs are also present in molecules such as the protein disulphide isomerases and the endothelial specific PDIs. Whereas PDIs protect endothelial cells during both normoxia and hypoxia, EndoPDIs are upregulated and protect during hypoxic stress (Sullivan et al, 2003). Future investigations of potential antiangiogenic mechanisms may involve effects of AW464 on these redox active molecules. Thioredoxin as a molecular target is upstream of several regulatory processes key to the survival of tumours. A potential thioredoxin inhibitor such as AW464 that targets both the tumour and endothelial cell represents an effective therapy for colorectal cancer. 


\section{REFERENCES}

Anema SM, Walker SW, Howie AF, Arthur JR, Nicol F, Beckett GJ (1999) Thioredoxin reductase is the major selenoprotein expressed in human umbilical-vein endothelial cells and is regulated by protein kinase C. Biochem J 342: $111-117$

Berggren M, Gallegos A, Gasdaska JR, Gasdaska PY, Warneke J, Powis G (1996) Thioredoxin and thioredoxin reductase gene expression in human tumors and cell lines, and the effects of serum stimulation and hypoxia. Anticancer Res 16: $3459-3466$

Berlin JD (2002) Targeting vascular endothelial growth factor in colorectal cancer. Oncology (Huntingt) 16(Supplement): 13-15

Bocci G, Nicolaou KC, Kerbel RS (2002) Protracted low-dose effects on human endothelial cell proliferation and survival in vitro reveal a selective antiangiogenic window for various chemotherapeutic drugs. Cancer Res 62: 6938-6943

Bossi P, Viale G, Lee KAC, Alfano RM, Coggi G, Bosari S (1995) Angiogenesis in colorectal tumours: microvessel quantitation in adenomas and carcinomas with clinicopathological correlations. Cancer Res 55: 5049-5053

Browder T, Butterfield CE, Kraling BM, Shi B, Marshall B, O’Reilly MS, Folkman J (2000) Antiangiogenic scheduling of chemotherapy improves efficacy against experimental drug-resistant cancer. Cancer Res 60: $1878-1886$

Carmichael J, DeGraff WG, Gazdar AF, Minna JD, Mitchell JB (1987) Evaluation of a tetrazolium based semi-automated colorimetric assay: assessment of chemosensitivity testing. Cancer Res 47: 936-942

Chun YS, Kim MS, Park JW (2002) Oxygen-dependent and -independent regulation of HIF-1alpha. J Korean Med Sci 17: 581 - 588

Dicker AP, Williams T, Grant DS (2001) Targeting angiogenic processes by combination of Rofecoxib and ionising radiation. Am J Clin Oncol (CCT) 24: $438-442$

Don AS, Kisker O, Dilda P, Donoghue N, Zhao X, Decollogne S, Creighton B, Flynn E, Folkman J, Hogg PJ (2003) A peptide trivalent arsenical inhibits tumor angiogenesis by perturbing mitochondrial function in angiogenic endothelial cells. Cancer Cell 3: 497-509

Drevs J (2003) Soluble markers for the detection of hypoxia under antiangiogenic treatment. Anticancer Res 23: 1159-1161

Ema M, Hirota K, Mimura J, Abe H, Yodoi J, Sogawa K, Poellinger L, Kuriyama Y (1999) Molecular mechanisms of transcription activation by HLF and HIF $1 \alpha$ in response to hypoxia: their stabilization and redox signal-induced interaction with CBP/p300. EMBO J 18: 1905-1914

Fernando MR, Nanri H, Yoshitake S, Nagata-Kuno K, Minakami S (1992) Thioredoxin regenerates proteins inactivated by oxidative stress in endothelial cells. Eur J Biochem 209: 917-922

Folkman J (1990) What is the evidence that tumours are angiogenesis dependent? J Natl Cancer Inst 82: 4-6

Frank RE, Saclarides TJ, Leurgans S, Speziale NJ, Drab EA, Rubin DB (1995) Tumor angiogenesis as a predictor of recurrence and survival in patients with node-negative colon cancer. Ann Surg 222: 695-699

Freshney RI (1994) Culture of Animal Cells: A Manual of Basic Technique 3rd edn. New York: Wiley-Liss, pp 200-201

Gately S, Kerbel R (2001) Antiangiogenic scheduling of lower dose cancer chemotherapy. Cancer J 7: 427-436

Harmey JH, Bouchier-Hayes D (2002) Vascular endothelial growth factor (VEGF), a survival factor for tumour cells: implications for antiangiogenic therapy. Bioessays 24: $280-283$

Hirano S, Cui X, Li S, Kanno S, Kobayashi Y, Hayakawa T, Shraim A (2003) Difference in uptake and toxicity of trivalent and pentavalent inorganic arsenic in rat heart microvessel endothelial cells. Arch Toxicol 77: $305-312$

Hirota K, Nakamura H, Masutani H, Yodoi J (2002) Thioredoxin superfamily and thioredoxin-inducing agents. Ann NY Acad Sci 957: $189-199$

Ishibashi H, Shiratuchi T, Nakagawa K, Onimaru M, Sugiura T, Sueishi K, Shirasuna K (2001) Hypoxia-induced angiogenesis of cultured human salivary gland carcinoma cells enhances vascular endothelial growth factor production and basic fibroblast growth factor release. Oral Oncol 37: $77-83$

Jaffe EA, Nachman RL, Becker CG, Minick CR (1973) Culture of human endothelial cells derived from umbilical veins: identification by morphologic and immunologic criteria. J Clin Invest 52: 2745-2756

Kabbinavar F, Hurwitz HI, Fehrenbacher L, Meropol NJ, Novotny WF, Lieberman G, Griffing S, Bergsland E (2003) Phase II, randomized trial comparing bevacizumab plus fluorouracil (FU)/leucovorin (LV) with FU/
LV alone in patients with metastatic colorectal cancer. J Clin Oncol 21: $60-65$

Kahlos K, Soini Y, Saily M, Koistinen P, Kakko S, Paakko P, Holmgren A, Kinnula VL (2001) Up-regulation of thioredoxin and thioredoxin reductase in human malignant pleural mesothelioma. Int J Cancer 95: $198-204$

Kakolyris S, Giatromanolaki A, Koukourakis M, Powis G, Souglakos J, Sivridis E, Georgoulias V, Gatter KC, Harris AL (2001) Thioredoxin expression is associated with lymph node status and prognosis in early operable non-small cell lung cancer. Clin Cancer Res 7: $3087-3091$

Le YJ, Corry PM (1999) Hypoxia-induced bFGF gene expression is mediated through the JNK signal transduction pathway. Mol Cell Biochem 202: $1-8$

Lechner S, Muller-Ladner U, Schlottmann K, Jung B, McClelland M, Ruschoff J, Welsh J, Scholmerich J, Kullmann F (2002) Bile acids mimic oxidative stress induced upregulation of thioredoxin reductase in colon cancer cell lines. Carcinogenesis 23: $1281-1288$

Lee JC, Chow NH, Wang ST, Huang SM (2000) Prognostic value of vascular endothelial growth factor expression in colorectal cancer patients. Eur J Cancer 36: $748-753$

Lichtenfels R, Kellner R, Atkins D, Bukur J, Ackermann A, Beck J, Brenner W, Melchior S, Seliger B (2003) Identification of metabolic enzymes in renal cell carcinoma utilizing PROTEOMEX analyses. Biochim Biophys Acta 1646: $21-31$

Liebmann JE, Cook JA, Lipschultz C, Teague D, Fisher J, Mitchell JB (1993) Cytotoxic studies of paclitaxel (Taxol) in human tumour cell lines. $\mathrm{Br} J$ Cancer 68: $1104-1109$

Mau BL, Powis G (1992) Inhibition of cellular thioredoxin reductase by diaziquone and doxorubicin. Relationship to the inhibition of cell proliferation and decreased ribonucleotide reductase activity. Biochem Pharmacol 43: 1621 - 1627

Meuillet EJ, Mahadevan D, Berggren M, Coon A, Powis G (2004) Thioredoxin-1 binds to the C2 domain of PTEN inhibiting PTEN's lipid phosphatase activity and membrane binding: a mechanism for the functional loss of PTEN's tumor suppressor activity. Arch Biochem Biophys 429: $123-133$

Miyazaki K, Noda N, Okada S, Hagiwara Y, Miyata M, Sakurabayashi I, Yamaguchi N, Sugimura T, Terada M, Wakasugi H (1998) Elevated serum level of thioredoxin in patients with hepatocellular carcinoma. Biotherapy 11: $277-288$

Pallis M, Bradshaw TD, Westwell AD, Grundy M, Stevens MF, Russell N (2003) Induction of apoptosis without redox catastrophe by thioredoxininhibitory compounds. Biochem Pharmacol 66: 1695-1705

Pantalone D, Ziche M, Messerini L, Pazzagli M, Morbidelli L, Parenti A, Donnini S, Palomba AR, Tricarico C, Paolucci R, Taruffi F, Andreoli F (1999) An angiogenesis study of Dukes' B colonic tumors. Clin Terapeut 150: $331-337$

Ponce ML (2001) In vitro Matrigel angiogenesis assays. In Methods in Molecular Medicine, 46 Angiogenesis Protocols Murray JC (ed) pp 205-209. Humana Press Inc.: Totowa, NJ

Powis G, Kirkpatrick DL, Angulo M, Baker A (1998) Thioredoxin redox control of cell growth and death and the effects of inhibitors. Chem Biol Interactions 111 - 112: $23-34$

Powis G, Montfort WR (2001) Properties and biological activities of thioredoxins. Annu Rev Biophys Biomol Struct 30: 421-455

Powis G, Welsh SJ, Kirkpatrick LD (2003) HIF1 as a cancer drug target: its inhibition and anti-tumour activity by PX-478. Programmes and Proceedings of the AACR-NCI-EORTC Conference on Molecular Targets and Cancer Therapeutics. p 254

Raffel J, Bhattacharyya AK, Gallegos A, Cui H, Einspahr JG, Alberts DS, Powis G (2003) Increased expression of thioredoxin-1 in human colorectal cancer is associated with decreased patient survival. J Lab Clin Med 142: 46-51

Saitoh M, Nishitoh H, Fujii M, Takeda K, Tobiume K, Sawada Y, Kawabata M, Miyazono K, Ichijo H (1998) Mammalian thioredoxin is a direct inhibitor of apoptosis signal-regulating kinase (ASK) 1. EMBO J 17: $2596-2606$

Saunders DE, Lawrence WD, Christensen C, Wappler NL, Ruan H, Deppe G (1997) Paclitaxel-induced apoptosis in MCF-7 breast cancer cells. Int J Cancer 70: $214-220$

Schallreuter KU, Wood JM (2001) Thioredoxin reductase - its role in epidermal redox status. J Photochem Photobiol B 64: 179-184 
Shao L, Diccianni MB, Tanaka T, Gribi R, Yu AL, Pullen JD, Camitta BM, Yu J (2001) Thioredoxin expression in primary T-cell acute lymphoblastic leukemia and its therapeutic implication. Cancer Res 61: 7333-7338

Sullivan DC, Huminiecki L, Moore JW, Boyle JJ, Poulsom R, Creamer D, Barker J, Bicknell R (2003) EndoPDI, a novel protein-disulfide isomerase-like protein that is preferentially expressed in endothelial cells acts as a stress survival factor. J Biol Chem 278: 47079-47088

Wells G, Berry JM, Bradshaw TD, Burger AM, Seaton A, Wang B, Westwell $\mathrm{AD}$, Stevens MF (2003) 4-Substituted 4-hydroxycyclohexa-2,5-dien-1ones with selective activities against colon and renal cancer cell lines. J Med Chem 46: $532-541$

Welsh SJ, Bellamy WT, Briehl MM, Powis G (2002) The redox protein thioredoxin-1 (Trx-1) increases hypoxia-inducible factor $1 \alpha$ protein expression: Trx-1 overexpression results in increased vascular endothelial growth factor production and enhanced tumor angiogenesis. Cancer Res 62: 5089-5095

Welsh SJ, Williams R, Berggren M, Kirkpatrick DL, Powis G (2003b) The anti-tumor activity of PX-478 an inhibitor of hypoxia-inducible factor- $1 \alpha$ $($ HIF- $1 \alpha)$ is associated with decreased HIF- $1 \alpha$ and plasma VEGF. Proceedings of the American Association for Cancer Research 94th Annual Meeting (2003), vol 44, p 1063 (abstract 4634)

Welsh SJ, Williams RR, Birmingham A, Newman DJ, Kirkpatrick DL, Powis G (2003a) The thioredoxin redox inhibitors 1-methylpropyl 2-imidazolyl disulfide and pleurotin inhibit hypoxia-induced factor $1 \alpha$ and vascular endothelial growth factor formation. Mol Cancer Ther 2: 235-243

Welsh S, Williams R, Kirkpatrick L, Paine-Murrieta G, Powis G (2004) Antitumor activity and pharmacodynamic properties of PX-478, an inhibitor of hypoxia-inducible factor- $1 \alpha$. Mol Cancer Ther 3: 233 244

Westwell AD, Berry JM, Bradshaw TD, Chew EH, Matthews CS, Monks A, Schwalbe CH, Stevens MF (2003) Phenolic oxidation products as novel antitumour agents. Programmes and Proceedings of the AACR-NCIEORTC Conference on Molecular Targets and Cancer Therapeutics, vol 186, no. C6

Xie K, Wei D, Shi Q, Huang S (2004) Constitutive and inducible expression and regulation of vascular endothelial growth factor. Cytokine Growth Factor Rev 15: 297 - 324

Zhong H, Chiles K, Feldser D, Laughner E, Hanrahan C, Georgescu MM, Simons JW, Semenza GL (2000) Modulation of hypoxia-inducible factor $1 \alpha$ expression by the epidermal growth factor/phosphatidylinositol 3-kinase/PTEN/AKT/FRAP pathway in human prostate cancer cells: implications for tumor angiogenesis and therapeutics. Cancer Res 60: $1541-1545$

Zhou J, Schmid T, Frank R, Brune B (2004) PI3K/Akt is required for heat shock proteins to protect hypoxia-inducible factor $1 \alpha$ from pVHLindependent degradation. J Biol Chem 279: 13506-13513 